\title{
Sensitization Sessions as the Foundation for Training Transformation Activities
}

\author{
Sacha Stoloff ${ }^{1,2,3}$, Maude Boulanger ${ }^{2,4}$, Virginie Roy $^{2,4} \&$ Marie-Claude Rivard ${ }^{1,2}$ \\ ${ }^{1}$ Université du Québec à Trois-Rivières, Department of Physical Education and Kinesiology, Trois-Rivières \\ (Quebec), Canada \\ ${ }^{2}$ Groupe interdiscipliniare de recherche appliquée en santé (GIRAS) \\ ${ }^{3}$ Centre de recherche interuniversitaire pour la formation et la profession enseignante (CRIFPE) \\ ${ }^{4}$ Université du Québec à Trois-Rivières, Department of Psychology, Trois-Rivières (Quebec), Canada \\ Correspondence: Sacha Stoloff, University of Quebec in Trois-Rivières, 3351, boul. des Forges, CP 500, \\ Department of Physical Education and Kinesiology, Trois-Rivières (Quebec), G9A 5H7, Canada. Tel: \\ 1-819-376-5011. E-mail: Sacha.Rose.Stoloff@uqtr.ca
}

Received: June 29, 2014

doi:10.5539/jel.v4n3p146
Accepted: July 23, $2015 \quad$ Online Published: August 19, 2015

URL: http://dx.doi.org/10.5539/jel.v4n3p146

\begin{abstract}
The worldwide rise in obesity makes this the first non-infectious epidemic in human history. The rapid increase is, in fact, influenced more by environment than biology. In an effort to halt the trend, Quebec has launched a major awareness-raising campaign that focuses on healthy environments and targets stakeholders in schools, municipalities, communities and the health sector. The purpose of the present study, then, is to determine how this campaign can promote action towards environments conducive to healthy lifestyles. The theoretical framework is based on planned change. The objectives are to 1) evaluate the quality of awareness-raising methods offered by trainers, and 2) place the impacts of the sessions into perspective. A qualitative approach was prioritized, consisting of two focus groups conducted with 17 trainers. From the standpoint of a healthy environment, sensitization sessions expanded networking, provided a common frame of reference and drove coherent actions for stakeholders involved. As an agent of change, the trainer played a key role in implementing the sessions. The conditions offered encouraged the transition from awareness to information, thereby generating significant results in terms of action. A sensitization session is thus a prerequisite for training transformation activities aimed in innovation.
\end{abstract}

Keywords: healthy environments, educational change, sensitization sessions, evaluation, trainers

\section{Literature Review}

\subsection{Introduction}

The World Health Organization (WHO) has alerted governments about the development of the first non-infectious epidemic in human history: obesity (Froguel, Guy-Grand, \& Clement, 2000). Although modern life has brought major advances, it has also contributed to obesity "epidemic". Developed societies foster the overconsumption of energy-rich foods, while individuals expend less and less energy (De Bandt, 2004). Industrialization and food processing, the sharp rise in home and industrial automation and the fast pace of modern life have strongly encouraged the development of sedentary lifestyles to the detriment of healthy living (Bouchard, 2000).

Indeed, many experts believe that the rapid rise in obesity is a result of environment rather than biology (Hill, Wyatt, Reed, \& Peters, 2003). Significant research highlights the contribution of four environments - physical, sociocultural, economic and political - that are likely to promote an active lifestyle and healthy food choices (Booth et al., 2001; Ministère de la Santé et des Services Sociaux [MSSS], 2012).

To date, numerous initatives to promote healthy environments have been implemented to train influential stakeholders to facilitate environments more conducive to healthy living (Cohen, Scribner, \& Farley, 2000). An evaluation and monitoring process is now required to appreciate the changes effected based on initial intention and anticipated degree of quality (Handicap International, 2008). 


\subsection{Background}

A number of measures and action plans have been implemented in countries throughout the world to fight obesity and promote healthy lifestyles; examples include the United States (Office of Disease Prevention and Health Promotion, 2014), Europe (Commission européenne, 2014) and Canada (Public Health Agency of Canada, 2010). In Quebec, the 2006-2012 Government Action Plan to Promote Healthy Lifestyles and Prevent weight-related Problems, entitled Investigating for the Future (MSSS, 2006), emphasizes the promotion of healthy lifestyles based on physical activity and healthy eating. This plan served as a lever for multiple networks of stakeholders focused on effective or promising actions to promote healthy lifestyles, including an approach aimed at facilitating more healthy environments. With this objective in mind, the Comité québécois de formation sur les saines habitudes de vie together with its collaborators launched a training program with the goal of sensitizing stakeholders in various sectors to the need and way to build healthy environments and promote active lifestyle and healthy food choices.

This training is unique in that it consists in 1) the sensitization phase for stakeholders, 2) the promising combination of four healthy environments (physical, sociocultural, economic and political), 3) the empowerment of sensitized stakeholders and, especially, 4) a vast population-based approach. In order to understand the meaning of the sensitization phase for stakeholders, it seems important to explain that it is the inception stage of training, which means the first contact with the group, the trainer, the global content, the goals to be attained, the structure of course and time distribution (Hourst, 2008). Such phase is crucial to create a climate for learning, to stimulate motivation and participants' engagement in futher meaningful activities (Desbiens, 2008). The sensitization phase should be the first step leading to change. This awareness raising method is explored in detail in section 1.3.

The main goal of this province-wide effort is to implement an innovation by 1) dispensing information regarding all four healthy environments needed to fight problems of obesity, 2) highlighting effects of these environments on lifestyles, and 3) identifying the means of action needed to build environments conducive to healthy lifestyles. This large-scale operation was piloted by some thirty trainers who had previously been trained to conduct sensitization sessions. Between September 2012 and June 2015, over 900 sensitization sessions ( 3 hours/session) were held across Quebec, with the participation of more than 14,000 stakeholders in schools, municipalities, communities and the health sector. Because of the importance of this project, the present article focuses on the evaluation of the sensitization sessions designed for stakeholders.

\subsection{Issue}

The relevance of involving stakeholders who can significantly influence the four environments is underscored in the literature (Cohen et al., 2000). These stakeholders include, among others, employees in schools, municipalities, and the health sector, all of whom have the potential to take action in their respective environments.

The potential to act is based on planned educational changes (Savoie-Zajc, 1993). Extensive research has attempted to pinpoint the factors governing the effectiveness of change (Cros, 2004), but there are significant limitations nonetheless. Said limitations involve a resistance to change (Butler-Kisber \& Crespo, 2006; Savoie-Zajc, 1993) caused by 1) intolerance for inconfort (Mongeau \& Tremblay, 2002), 2) supremacy of an established culture (Brunelle, 2000; Perrenoud, 2000), and 3) persistence of habits (Brunelle, 2000). In this regard, Savoie-Zajc (1993) divides the resistance factors into three key categories: 1) nature of the system, often overly complex, together with hard-to-measure objectives, 2) absence of sensitization to the very notion of change, and 3) deficient communication networks.

Until now, ongoing training has been presented as an option required to maintain or broaden professional knowledge and expertise (Legendre, 2005) in order to effect change and achieve innovation. In the literature, training methods are examined and a number of shortcomings are underscored, including 1) insufficient consideration of learners' preferential learning method (Fleurance \& Cotteaux, 1999; Perrenoud, 2000; Renard, 2000), 2) too much information dispensed in too short a time (Gilbert \& Trudel, 2005), or 3) content strongly based on a program rather than on trainees' needs (Gilbert \& Trudel, 2005; Jarvis, 2006; Riding, 2001; Savoie-Zajc, 2007). Conversely, training methods are effective if learners can relate the content taught to their professional needs (Knowles, Holton, \& Swanson, 2005). In this case, what is learned has meaning in that it allows learners to connect theory and practice (Hourst, 2008).

At the same time, a relatively little-documented but promising training method concerns the inception stage of training, also called the connection phase (Hourst, 2008), preparation stage (Desbiens, Roy, Spallanzani, Brunelle, \& Lacasse, 2005) or sensitization stage (Lamoureux, 2002). On the one hand, this stage concerns relationship and involves the creation of an optimal state of receptivity for teaching and learning. On the other hand, it takes into 
account content quality, characterized by the presentation of an attractive overall image of learning and the identification of anchor points. The purpose of this sensitization stage is to foster learning and motivate action. Despite the importance of defusing possible resistances and encouraging learner-centred training, few studies have examined the stage prior to planned change training-transformation process. For this reason our research question is formulated as follows: how can sensitization sessions incite the various stakeholders to take action towards healthy environments?

\subsection{Conceptual Frameworks}

From the perspective of planned change, two interdependent systems must be considered-the user system, which aims to implement an innovation, and the resource system, which supports the former in meeting the objectives for change. In this regard, Hall's 1973 model remains highly regarded in education because it allows us to capture the essence of the dimensions leading to innovation and the underlying interactions between the systems (Savoie-Zajc, 1993). The model has had significant impact in many fields.

In Hall's model, the role of the user system involves 1) analyzing needs to respond to a real-life problem, 2) considering change, and 3) establishing the limitations of the approach planned (Savoie-Zajc, 1993). The resource system, for its part, is charged with proposing appropriate conditions to achieve fixed objectives. Toward these ends, the agent of change acts as an intermediary between the two systems (see Figure 1).

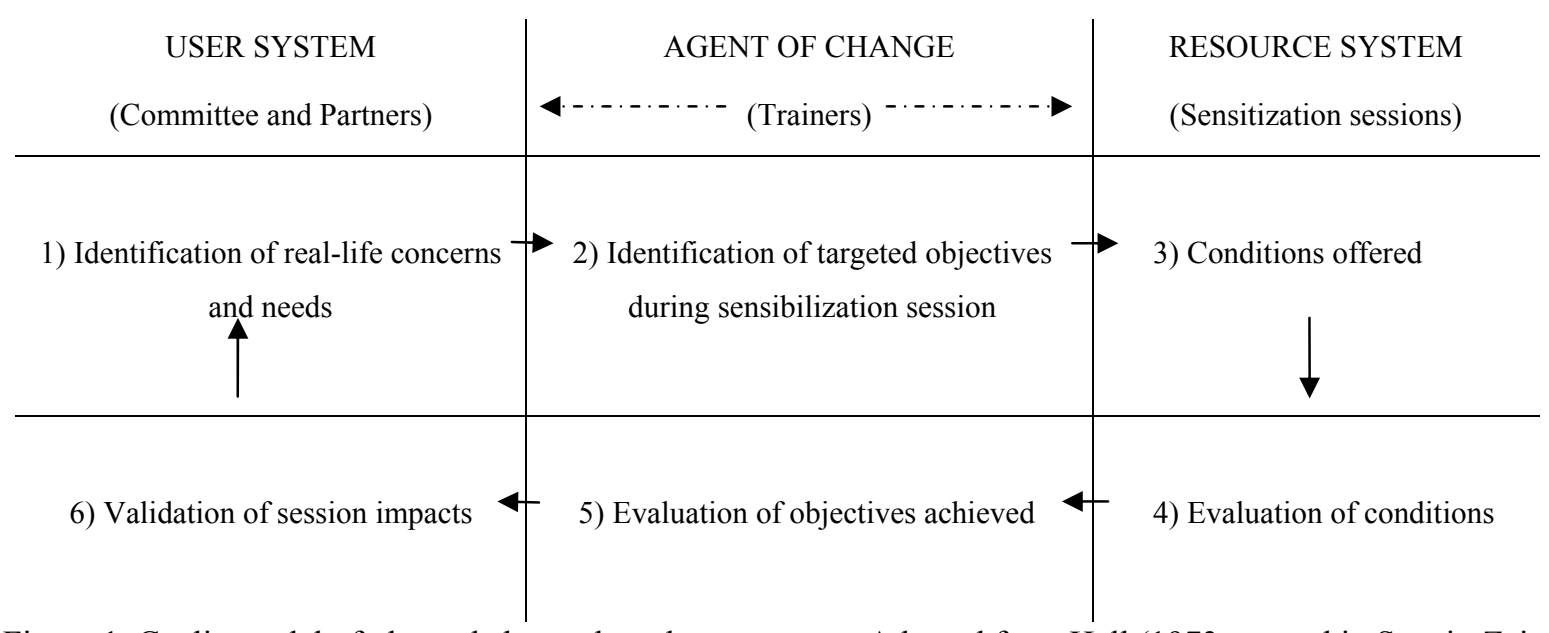

Figure 1. Cyclic model of planned change based on concerns. Adapted from Hall (1973; quoted in Savoie-Zajc, 1993).

Alongside this model, Hall believes that change occurs in pace with the evolving concerns of the persons trained, which can move through levels going from awareness to innovation (1973; quoted in Savoie-Zajc, 1993). Thus, the role of the agent of change is to sensitize individuals on the meaningfulness and options of change, then stimulate the transition from one level of concern to another. During sensitization sessions, the goal is to stimulate the transition from stakeholders' awareness to relevant information based on the possible guidelines for change needed to facilitate environments conducive to healthy lifestyles.

\subsection{Objectives of the Study}

The objectives of the present study are to: 1) evaluate the quality of the sensitization conditions offered by trainers, and 2) place the impacts of the sensitization sessions into perspective.

\section{Method}

\subsection{Participants}

Our study employed a qualitative approach as part of a descriptive and interpretative approach aimed at achieving our research objectives (Poupart, 2011; Savoie-Zajc, 2009). The sample is intentional: solicited participants represent all the trainers who, as part of their function as public health officers, deliver these sessions $(n=30)$. Participants from all 16 regions of Quebec were therefore targeted according to their expertise, their activities in the issue under study and their agreement to discuss their experience (Savoie-Zajc, 2009). The process leading to their participation started at an annual meeting where the research group was invited to present the research project. 
All the details and ethical approach were presented for those interested to be able to sign the consent form. The only selection criterion was that the trainer must have experienced dispensing sensitization sessions to stakeholders. In total, 17 out of 30 trainers (57\%) accepted to participate in the study, and represent 15 of the 16 regions of Quebec. Two focus groups were divided as follow: Group $A=8(F)$, Group $B=9(F)$. Whenever two trainers were from the same region, they would be in different groups.

\subsection{Tool}

The focus group fosters in-depth understanding of the study topic; it offers a flexible interrogation method and generates a wealth of data making it possible to introduce new topics and lead the discussion in different directions (Geoffrion, 2003). A non-directive moderator style is emphasized, which ensures a certain control of the discussion by privileging participant interaction; this results in new statements (Geoffrion, 2003), idea sharing and expression of nuances (Baribeau, 2010).

The focus groups lasted an average of 90 minutes each and were guided by 11 questions divided into two major themes. The first theme focused on effectiveness of sessions. Questions were oriented towards 1) general conditions offered to stakeholders, 2) goal attainability, and 3) content quality. The second theme focused on impacts. Questions were oriented towards 1) vision changes, 2) knowledge acquisition and 3) roles played by trainers. Thus, the focus group was based on a semi-structured process in order to enhance open answers. Such method was valued since it offers a wider range of ideas thanks to different topics adressed, new contents emerging and most of all, improved discussion between trainers (Baribeau, 2010). Each question asked insured time and open-minded climate for each participant to speak freely and expose personal experience. Once the trainers had exposed their views and had nothing to add, the moderator moved on to the next question.

\subsection{Analysis Strategy}

Both group interviews were audiotaped and fully transcribed. A deductive content analysis (Patton, 2002) was conducted based on the categories of Hall's model (1973; quoted in Savoie-Zajc, 1993) and is described in the section Conceptual frameworks. The analysis strategy included four stages adapted from Boutin (2007): 1) preliminary readings, 2) grouped statements, 3) identification of sub-categories and 4) description of findings. Use of the NVivo software facilitated the delineation, coding and grouping of units of meaning, the emergence of sub-categories and the analysis of the similarities and differences noted in the comments of the various participants. The strict coding process was conducted by two coders, and a third coder validated $20 \%$ of the corpus (rate of fidelity 95\%), leading to a final classification by consensus (Yardley, 2008).

\section{Findings}

The findings are presented according to the study's objectives. Each participant $(\mathrm{P})$ is identified in function of his focus group (A or B) with a code number (1 to 9). For example, P.A.1 is the participant in focus group A identified by the number 1 .

\subsection{Objective 1: Quality of Awareness-Raising Methods}

\subsubsection{Adherence to the Vision of Healthy Environments}

Conducting a sensitization session enabled trainers to rely on a preestablished frame of reference to present and explain healthy environments to stakeholders. At the same time, participants are initiated to a transversal vision of healthy environments depending on their area, which leads to the development of differentiated arguments: "I'd say my vision hasn't changed, necessarily, but I agree precisely because it lets me be much more transversal [...]. In consequence, there are a lot more arguments based on the different professional areas, so I developed a much better pitch that takes these different visions into account" (P.A.1).

Beyond this integrated vision, trainers point out that sessions favoured a shared perspective and terminology regarding healthy environments between participants: "[The stakeholders] now share a common language and vision, it makes quite a difference" (P.B.3). This is apparent in a new awareness on opportunities for environment changes. For example, the installation of distribution machines offering healthy snacks is a good opportunity to enhance healthy choices. The shared perspective is also expressed by a desire and potential for new collaborations: “...this really expanded our network of partners" (P.A.3).

\subsubsection{Trainer's Role Modification}

Although the trainer's primary role was te be a moderator, trainers were unanimous in stressing the multiple roles they performed during sessions. They underscored the need to act in multiple capacities as a planner, rercruiter/salesperson, organizer and accompanier. For example, one trainer described his experience in these words: “A year later, I realize my role isn't just to conduct sessions, that's the easiest part. It's to go recruit 
participants, only I was never trained for recruiting and I found left alone. They told me to draw a map. A map! That sounds good, but how do I do it? Who with? How long does it take?"(P.B.7).

\subsubsection{Adaptation of Sessions}

Trainers say that, although the session is part of a preestablished framework and structure, it's both necessary and desirable to adapt it to the stakeholders. They pointed out that to engage the participants, content must be adjusted to regional or local realities and concrete examples must be taken from the various contexts: "I adapted things based on what I got here, not necessarily something from the chief committee. As a matter of fact, the good things I got and brought back to the session came from previous participants" (P.A.6).

On the other hand, the need to respect copyright has limited the adaptation of sessions to some extent, since the established framework narrowed how far they can go in modifying content: “... I realize that for the session to go well, I'm going to have to modify certain things. But then they tell me no, I can't do this, I can 't do that" (P.B.9). For other trainers, the effort to adapt is seen as an additional task that calls for extra preparation time. To illustrate: "...having to adapt it to each one of the target groups, which means each one of the sectors, takes a lot of work, of time... (P.A.5). Generally speaking, trainers view the predetermined content as an inconvenience that hinders them from adapting the session to the stakeholders' profile. More specifically, the content on obesity's statistics is perceived as difficult for both trainers and stakeholders: "We all realized after the sessions that the section on obesity was overlaoded..." (P.B.1).

Finally, concerning sensitization conditions, trainers prefer three-hour sessions because, in contrast to the six-hour sessions, the three-hour format is easier to organize and to integrate into the stakeholders' schedules, and the lighter content is easier to convey. As a result, content quality seems more stimulating and more meaningful.

\subsection{Objective 2: Impacts of the Sessions}

\subsubsection{Adequacy of Objectives}

A number of positive elements emerge from the analysis of the focus groups in connection with targeted aims. There is a consensus among trainers regarding the first two objectives, which are 1) dispensing information regarding healthy environments (physical, sociocultural, economic and political) needed to fight problems of obesity, and 2) highlighting effects of these environments on lifestyles. However, this does not appear to be the case for the third objective, which consists in reflecting the means of action: "[...] The first and second [objectives] in each session, we can pretty well deal with, but as for the third [...] we'd really have to think about it, we'd have to put in almost three hours at least" (P.A.1). Furthermore, the trainers questioned the first objective by criticizing the focus on obesity during sessions, since they feel a bit uncomfortable addressing this often sensitive topic: "[...] even if you know there's an urgent need for action, at some moments, you realize you're uncomfortable because we're talking about obesity" (P.B.1).

\subsubsection{Move across Levels of Concern}

When asked about the sessions' impacts, several trainers observed that the stakeholders made changes from the standpoint of environments conducive to healthy lifestyles. As an example, one emerging change involved improving action plans and strategic planning: "And then they even included the four environments in strategic planning. It wasn't perfect, I'm not describing a dream, but during one of the meetings, they [the stakeholders] really mentioned the four environments. I found it interesting that they kept on with this because they transmitted the healthy environment message to the others" (P.A.2). Another impact concerns use of the communication networks. The stakeholders started recommending the session to other colleagues, which multiplies the sensitization sessions given in any one area: "The most concrete example is when we're invited back. People [...] call on us again to go to their area, that's when I see the positive effects" (P.A.1). However, the trainers note that it's difficult to learn precisely what concrete actions sensitized stakeholders are taking to promote -environments: "For me, an impact means that people in an area are mobilized to build healthy environments, but unfortunately, we trainers aren't necessarily aware of what they end up by doing" (P.B.7).

These findings highlight the effectiveness of conditions offered during sensitization sessions since they can potentially motivate stakeholders to take action in terms of the impacts for more healthy environments.

\section{Discussion}

It should be recalled that the present study focuses on the professional training offer of the user system, whose province-wide innovation aims to promote environments. The main concern was the implementation of sensitization sessions for stakeholders in various contexts such as schools, municipalities, communities and health sectors. The objectives were to evaluate the quality of the methods used by the trainers and to place the impacts of 
the sessions into perspective. To these ends, the connection between the resource system and the user system was possible insofar as it was created, supported and funded. A planned, structured and systematic approach was deployed across the environments and regions. Findings show the relevance of this type of training arrangement based on the implementation of planned large-scale and multisectoral changes. They are discussed in the following section.

\subsection{Objectve 1: Quality of Awareness-Raising Methods}

This study's findings reveal that in view of planned change, communication networks cannot be set up in the absence of a shared terminology and vision, derived from a central reference framework. Indeed, Savoie-Zajc (1993) highlights the importance of a shared vision for sustaining and perpetuating innovation. The agent of change becomes a crucial leader for introducing this vision and persuading stakeholders to adhere to it (Kouzes \& Posner, 1993). Accordingly, trainers have also allowed sensitized actors to adopt a shared terminology and vision in relation to healthy environments, indicating that new actions and partnerships for building such environments can now be expected (MSSS, 2012).

In the beginning, the sole role of the agent of change was to moderate sessions in keeping with the targeted objectives of the user system. Then, to the surprise of the trainers questioned, this role turned out to be much broader. Trainers had, in fact, assumed numerous roles including those of liaison, change and mobilization agent to conduct the sensitization sessions (Higgins, Douglas, \& Muirie, 2005). As for Hourst (2008), these multiple roles doubtlessly contributed to the value-even credibility-of the trainers thanks to the shift from moderator to leader. These findings convey with the idea that the greater the role, the stronger the individual's sense of commitment (Stoloff, 2012).

Moreover, the level of commitment is demonstrated throughout the adapted sessions, which the trainers tailored to the needs of the stakeholders and their environments. This is consistent with the conclusions of Knowles et al. (2005), who recall the importance of these two elements for effective change. These findings are unique in that the adaptations were initiated and conducted by the trainers themselves. Furthermore, the latter made it known that such initiatives call for substantial preparation, but were needed to conduct the sessions with optimal efficiency.

For the purposes of the present study, the adapted sessions focused on format and even contents. In this regard, trainers noted a certain discomfort concerning obesity as a core theme for discussing healthy environments. This refers back to the sensitivity of the topics covered (Gilbert \& Trudel, 2005) owing to the many possible interpretations by agents of change.

\subsection{Objective 2: Impacts of the Sessions}

This study reveals that the objectives targeted by the session were deemed adequate and realistic, which suggests less resistance to change in future (Savoie-Zajc, 1993). In contrast to Savoie-Zajc (1993), a nuance must be made regarding the negative impact of complexity in the resource system, here considered an asset for planned change. Indeed, this complexity may represent a multitude of opportunities for change via an expanded communication network and intersectoral projects. This urges us to examine the duality of complexity, which may enrich and stimulate planned change or, conversely, suppress and halt it.

The purpose of the sensitization sessions was to stimulate the transition from awareness to information. On the one hand, they attempted to sensitize actors, which was achieved thanks to strategies of information, clarification, comprehension and exposition based on a common referential. On the other, the aim was to motivate participants to take action, which was achieved through strategies of identification and recognition of the opportunities for change. Interestingly enough, findings show that the sessions had an impact beyond awareness-raising in that concrete actions have been implemented in various contexts. In reference to Hall's concern levels, this therefore reflects the transition from awareness level to information level, which involves owning and sharing the vision and the knowledge dispensed.

\section{Conclusion}

This research demonstrates that a sensitization session is a precondition for training transformation activities. The sensitization stage must therefore be privileged to ensure large-scale planned changes at the start of an innovation.

In the present context, the sessions offered are distinguished in terms of size, format and content from everything currently being done in Quebec in terms of healthy lifestyles. This approach appears to promote networking and adherence to a common frame of reference and, as a result, the development of coherent, sustainable actions, an important first step towards building healthy environments. New approaches to healthy lifestyles are emerging in 
Quebec, and the article in hand is an opportunity to share and consolidate the knowledge and expertise relative to promotion and training that are deemed promising for persuading Quebecers to adopt a healthy and active lifestyle.

Trainers played a decisive role in the implementation of sensitization sessions that occur prior to general professional training. Thus, from the standpoint of large-scale and ongoing training, it can be concluded that a sensitization stage is a lever for stimulating transition across levels of concern for the purpose of achieving a targeted innovation. Finally, we believe it would be a good idea to explore a similar educational approach in other professional fields in order to better understand the mechanics and scope of sensitization sessions.

\section{Acknowledgements}

The authors wish to express their thanks to Pascal Dubreuil and Sébastien Blanchette, students at the Université du Québec à Trois-Rivières, for their work collecting data. Also, many thanks to Quebec en Forme for its financial support.

\section{References}

Agence de la Santé Publique du Canada. (2010). Maladies Chroniques et obésité au Canada [Chronic Disease and Obesity in Canada]. Retrieved from http://www.phac-aspc.gc.ca/hp-ps/hl-mvs/ipchls-spimmvs/sum-res-fra.php

Baribeau, C. (2010). L'entretien de groupe: Considérations théoriques et méthodologiques [Focus Group: theoretical and methodological considerations]. Recherches Qualitatives, 29(1), 28-49.

Booth, S. L., Sallis, J. F., Ritenbaugh, C., Hill, J. O., Birch, L. L., Frank, L. D., \& Hays, N. P. (2001). Environmental and societal factors affect food choice and physical activity: Rationale, influences, and leverage points. Nutrition Reviews, 59(3), 21-39. http://dx.doi.org/10.1111/j.1753-4887.2001.tb06983.x

Bouchard, C. (2000). Physical Activity and Obesity. In C. Bouchard (Ed.), Introduction (pp. 3-19). Human Kinetics, Champaign Illinois.

Boutin, G. (2007). L'entretien de groupe en recherche et formation [Focus group for research and training]. Montréal: Éditions nouvelles.

Brunelle, J. (2000). Quand un stage vise le développement de la réflexivité des enseignants-stagiaires [When pre-service training aims teacher's reflexivity development]. In G. Carlier, J.-P. Renard, \& et L. Paquay (Eds.), La formation continue des enseignants: Enjeux, innovation et réflexivité (pp. 83-109). Bruxelles: De Boeck \& Larcier.

Butler-Kisber, L., \& Crespo, M. (2006). Réflexion sur le développement professionnel en éducation [Reflection on professional development in education]. In M. Amyot, \& et C. Hamel (Eds.), La formation continue des personnels de l'éducation (pp. 9-22). Boisbriand: Éditions MultiMondes.

Cohen, D. A., Scribner, R. A., \& Farley, T. A. (2000). A structural model of health behavior: A pragmatic approach to explain and influence health behaviors at the population level. Preventive Medicine, 30(2), 146-154. http://dx.doi.org/10.1006/pmed.1999.0609

Commission Européenne. (2014). Programme d'action de l'Union dans le domaine de la santé (2014-2020) [Union's action program for health]. Journal officiel de l'Union européenne. Retrieved from http://eur-lex.europa.eu/legal-content/FR/TXT/HTML/?uri=CELEX:32014R0282\&from=EN

Cros, F. (2004). La recherche en éducation: Une nouvelle forme d'accompagnement de l'innovation, entre acteurs et décideurs politiques [Educational research: a new form of innovationnal support among stakeholders and policy makers]. In G. Pelletier (Ed.), Accompagner les réformes en éducation (pp. 101-124). Paris: Harmattan.

De Bandt, J. P. (2004). Nutrition et obésité [Nutrition and obesity]. Nutrition clinique et métabolisme, 18(3), 147-155. http://dx.doi.org/10.1016/j.nupar.2004.06.005

Desbiens, J.-F., Roy, M., Spallanzani, C., Brunelle, J.-P., \& Lacasse, G. (2005). Élaboration d'un outil pour décrire et analyser la communication pédagogique chez des étudiants-stagiaires en enseignement de l'ÉPS [Developing a tool for describing and analyzing pedagogical communication among HPE pre-service teachers]. Oral communication. Troisième biennale de l'Association pour la recherche sur l'intervention en sports (ARIS). Intervenir dans les activités physiques, sportives et artistiques: Du débutant à l'expérimenté. Pratiques, recherches, formations. Université catholique de Louvain (UCL) (Louvain-la-Neuve), Institut d'éducation physique et de réadaptation (IEPR), Unité Éducation par le mouvement (EDPM), 20 au 22 janvier. 
Fleurance, P., \& Cotteaux, V. (1999). Construction de l'expertise chez les entraîneurs sportifs d'athlètes de haut niveau français [Expertise construction among sports coaches dealing with French high level athletes]. Avante, 5, 54-68.

Froguel, P., Guy-Grand, B., \& Clement, K. (2000). Génétique de l'obésité: Vers la compréhension d'un syndrome complexe [Obesity genetics: understanding a complex syndrome]. La Presse Médicale, 29(10), 564-571.

Geoffrion, P. (2003). Le groupe de discussion [Then focus group]. In B. Gauthier (Ed.), Recherche sociale. De la problématique à la collecte de données (pp. 333-356). Québec, Sainte-Foy: Presses de l'Université du Québec.

Gilbert, W., \& Trudel, P. (2005). Learning to coach through experience: Conditions that influence reflection. The physical educator, 62(1), 32-43.

Higgins, M., Douglas M., \& Muirie, J. (2005). Can health feasibly be considered as part of planning process in Scotland? Environmental Impact Assessment Review, 25(7-8), 723-736. http://dx.doi.org/10.1016/j.eiar.2005.07.005

Handicap International. (2008). Guide pratique: réaliser une action de sensibilisation à la situation des personnes handicapées [Practical guide: Achieve awareness regarding disabled people's situation]. Handicap International.

Hill, J. O., Wyatt, H. R., Reed, G. W., \& Peters, J. C. (2003). Obesity and the environment: Where do we go from here? Science, 299, 853-855. http://dx.doi.org/10.1126/science.1079857

Hourst, B. (2008). Former sans ennuyer: Concevoir et réaliser des projets de formation et d'enseignement [Professional training without boring: Design and implement projects for training and teaching]. Paris: Eyrolles.

Jarvis, P. (2006). The theory and practice of teaching. London: Routledge.

Knowles, M. S., Holton III, E. F., \& Swanson, R. A. (2005). The adult learning: The definitive classic in adult education and human resource development (6th ed.). Burlington: Elsevier.

Kouzes, J. M., \& Posner, B. Z. (1993). Inventaire des pratiques du leadership: Auto-évaluation et analyse [Inventory of Leadership Practices: Self Evaluation and Analysis]. Montréal: Actualisation.

Lamoureux, H. (2002). La pratique de l'action communautaire [The practice of Community action]. Québec: Québec Presses de l'Université du Québec.

Légendre, R. (2005). Dictionnaire actuel de l'éducation [Current dictionary in education]. Montréal: Guérin.

Ministère de la Santé et des Services Sociaux. (2006). Investir pour l'avenir [Investing for the future]. Plan d'action gouvernemental de promotion des saines habitudes de vie et de prévention des problèmes reliés au poids 2006-2012. Québec: Gouvernement du Québec.

Ministère de la Santé et des Services sociaux. (2012). Pour une vision commune des ennvironnments favorables à la saine alimentation et à la prévention des problèmes reliés au poids [For a common vision related to favorable environments regarding healthy diet and prevention of weight-related problems]. Document rédigé en collaboration avec Québec en Forme et l'Institut National de la Santé Publique du Québec (INSPQ), Québec: Gouvernement du Québec.

Mongeau, P., \& Tremblay, J. (2002). Survivre: La dynamique de l'inconfort [Surviving: Discomfort dynamics]. Sainte-Foy: Presses de l'Université du Québec.

Office of Disease Prevention and Health Promotion. (2014). About Healthy people. Departments of Health and Human Services. Office of Disease Prevention and Health Promotion.

Patton, M. Q. (2002). Qualitative Research and Evaluation Methods. Thousand Oaks, CA: SAGE Publications.

Perrenoud, P. (2000). Du concret avant toute chose... ou comment faire réfléchir un enseignant qui veut agir [Practical above all ... or how to favor thinking with a teacher who wants to act]. In G. Carlier, J-P. Renard, \& et L. Paquay (Eds.), La formation continue des enseignants: Enjeux, innovation et réflexivité (pp. 69-82). Bruxelles: De Boeck \& Larcier.

Poupart, J. (2011). Tradition de Chicago et interactionnisme: Des méthodes qualitatives à la sociologie de la déviance [Chicago tradition and interactionism: Qualitative methods in sociology of deviance]. Recherches qualitatives, 30(1), 178-199. 
Renard, J.-P. (2000). Le point de vue des enseignants en formation [Trainee teachers' point of view]. In G. Carlier, J-P. Renard, \& et L. Paquay (Eds.), La formation continue des enseignants (pp. 35-46). Bruxelles: De Boeck et Larcier.

Riding, P. (2001). Online teacher communities and continuing professional development. Teacher development, 5(3), 283-296. http://dx.doi.org/10.1080/13664530100200156

Savoie-Zajc, L. (1993). Les modèles de changement planifié en éducation [Models for planned change in education]. Québec: Les éditions Logiques.

Savoie-Zajc, L. (2007). L'accompagnement aux ajustements de pratiques professionnelles de personnels scolaires par la recherche-action [Supporting school personnel in adjusting professional practices through action research]. In F. Cros (Ed.), L'agir innovationnel: Entre créativité et formation (pp. 63-76). Bruxelles: De Boeck.

Savoie-Zajc, L. (2009). L'entrevue semi-dirigée [Semi-structured interview]. In B. Gauthier (Ed.), Recherche sociale: De la problématique à la collecte de données (pp. 337-360). Québec: Presses de l'Université du Québec.

Stoloff, S. (2012). Recherche-action sur l'implantation d'un processus de supervision pédagogique classique auprès d'intervenants experts en activité physique en vue de l'intégration de pratiques de formation. Thèse de doctorat, Université de Sherbrooke, Sherbrooke.

Yardley, L. (2008). Demonstrating validity in qualititive research. In J. A. Smith (Ed.), Qualitative psychology: A practical guide to research methods (pp. 235-251). London: Sage.

\section{Copyrights}

Copyright for this article is retained by the author(s), with first publication rights granted to the journal.

This is an open-access article distributed under the terms and conditions of the Creative Commons Attribution license (http://creativecommons.org/licenses/by/3.0/). 